Anales de Geografía de la Universidad Complutense ISSN: 0211-9803

http://dx.doi.org/10.5209/AGUC. 62482

\title{
El fracaso del planeamiento urbanístico actual de la ciudad de Toledo: el Plan de Ordenación Municipal de 2007
}

\author{
Luis Alfonso Escudero Gómez ${ }^{1}$ \\ Recibido: 6 de febrero del 2017/ Enviado a evaluar: 21 de junio del 2017/ Aceptado: 18 de octubre del 2018
}

Resumen. Toledo es una ciudad histórica. Su urbanización contemporánea se ha expandido de forma dispersa, desestructurada y desarticulada. El Plan de Ordenación Municipal aprobado en 2007 pretendía resolver esta disfuncionalidad de una forma sostenible. El artículo demuestra el fracaso del plan y la necesidad de un nuevo urbanismo. El plan planteaba un modelo territorial erróneo con una expansiva calificación de suelo urbanizable y una promoción masiva de viviendas. Se aplica una metodología analítica crítica con la utilización de múltiples referencias bibliográficas, noticias de prensa, estadísticas, sentencias judiciales, SIG y el propio plan. La investigación y sus resultados son aplicables de forma comparativa a otras ciudades que aún cuentan con un urbanismo desarrollista.

Palabras clave: Geografía Urbana; urbanismo; planeamiento urbanístico; España; Toledo.

\section{[en] The failure of the current urban planning of the city of Toledo: the Municipal Plan of 2007}

\begin{abstract}
Toledo is not only a historical city, but one that has been developed haphazardly in a disjointed and unstructured manner. In 2007, the Municipal Urban Zoning Plan established its main purpose as to resolve this dysfunctionality in a sustainable way. The objective of this article is to demonstrate that this plan has foundered and it is necessary to consider a newer and more urbanised city planning model. The plan took into consideration an erroneous territorial model with an expansive land development classification that includes extensive housing development. We have implemented an analytical and critical methodology based upon multiple sources, such as literature, the press and other direct sources: statistics, judicial rulings, GIS and the plan itself. This research and its findings are comparatively applicable to other cities where there is an expansive urban development model in place.
\end{abstract}

Key words: Urban Geography; town planning; urban planning; Spain; Toledo.

1 Departamento de Geografía y Ordenación del Territorio. Universidad de Castilla-La Mancha.

E-mail: luisalfonso.escudero@uclm.es 
[fr] L'échec de l'urbanisme actuel de la ville de Tolède: le plan municipal de 2007

Résumé. Tolède est une ville historique, mais aussi une ville avec une urbanisation récente non structurée et dispersée. En 2007, un plan municipal urbain a établi son principal objectif afin de résoudre cette dysfonctionnalité de façon durable. L'objectif de cet article est de démontrer que ce plan a fondu et qu'il est nécessaire d'envisager un nouveau modèle de planification urbaine. Le plan avait un modèle territorial erroné: le développement massif du logement. Nous appliquons une méthodologie analytique et critique basée sur de multiples sources, comme la littérature, la presse et d'autres sources directes: statistiques, décisions judiciaires, SIG et le plan lui-même. Cette recherche et ses résultats sont comparativement applicables à d'autres villes où il existe un modèle expansif de développement urbain en place.

Mots clés: Géographie Urbaine; urbanisme; aménagement urbain; Espagne; Tolède.

Cómo citar. Escudero Gómez, L.A. (2018): El fracaso del planeamiento urbanístico actual de la ciudad de Toledo: el Plan de Ordenación Municipal de 2007. Anales de Geografía de la Universidad Complutense, 38(2), 313-339

Sumario. 1. Introducción. 2. Resultados. 2.1. Elección del modelo urbano desarrollista y ¿su actual final? 2.2. El fracaso del planeamiento urbanístico toledano actual. 2.2.1. El contexto urbanístico de Toledo a inicios de siglo, el proceso de elaboración del POM, sus objetivos principales y el «salto adelante» de 2005 a 2007. 2.2.2. Un planeamiento urbano muy desarrollista. 2.2.3. Un planeamiento urbano con un accidentado periplo judicial. 2.2.4. Un planeamiento sobre el papel no ejecutada por la crisis. 2.3. Propuestas urbanísticas para el futuro de Toledo. 3. Discusión 4. Conclusión. 5. Referencias bibliográficas.

Sino que todo era expansión urbanistica, y más expansión, y más expansión; y el desarrollo urbanistico de baja densidad es lo peor que hay. (Jonathan Franzen, Libertad, 2011, p. 165).

\section{Introducción}

Toledo es una urbe de pequeño tamaño demográfico (83.459 habitantes a 1 de enero de 2016 -INE). Es conocido globalmente por su centro histórico declarado como Patrimonio de la Humanidad de la UNESCO en 1986. Hoy es un destino turístico cultural consolidado a nivel doméstico e internacional (Troitiño, 2005). También se trata de una ciudad con una relevante multifuncionalidad: capital autonómica, centro de servicios y área industrial. Toledo se ha expandido más allá de su recinto histórico. El casco antiguo es actualmente un espacio minoritario. Este crecimiento urbanístico ha dado pie a una ciudad fragmentada y muy diseminada en el territorio.

Esta realidad se pretendía mejorar mediante el Plan de Ordenación Municipal (POM) de 2007. La pregunta principal de la presente investigación surge en este punto: ¿es el POM de Toledo el modelo territorial necesario para la ciudad de Toledo? En caso de respuesta negativa, ¿cuál debería ser? 
Los estudios académicos de Toledo sobre el turismo cultural y su centro histórico son muy numerosos. Los trabajos acerca de la planificación urbana abundan menos. Además, algunos toman al casco antiguo como su espacio central de referencia: la destacable monografía de Zárate y Vázquez de 1982 y las investigaciones posteriores de Campos et al. en 1988 y López en 2005. Zarate en 2007 también lo hacía en esta misma revista. Su artículo es el precedente directo de esta investigación. Zárate ya analizaba de manera muy crítica el POM de Toledo en el mismo año de su aprobación. El presente trabajo es una actualización de su obra pasada una década. Procesos como las dificultades judiciales del POM y los efectos de la crisis económica de 2008 en la actividad constructiva e inmobiliaria de la ciudad ${ }^{2}$ hacen necesaria una revisión. Otras referencias bibliográficas sobre la temática se interesan por determinados sectores de la ciudad como la Vega Baja (Campos y Escudero, 2007 y Peris y Villa, 2009) o el polígono residencial de Santa $\mathrm{M}^{\mathrm{a}}$ de Benquerencia (Escudero y Gómez, 2007). Finalmente, también se han publicado diferentes estudios arquitectónicos sobre el urbanismo de la ciudad: Fariña en 1993, Álvarez en 2004 y 2017 y Muelas y Parrilla (los autores del POM) en 2008.

Los objetivos específicos de la investigación son:

-Entender el modelo de urbanismo aplicado en la ciudad.

-Demostrar que el POM de 2007 ha fracasado.

-Razonar que el modelo territorial del POM es erróneo.

-Proponer un urbanismo distinto en Toledo.

La estructura del artículo se adapta a estos objetivos. El primer apartado es introductorio. El segundo son los resultados. Tras unas reflexiones generales sobre el modelo urbano desarrollista y su posible final en el presente, se trata el caso de estudio. Se describe el contexto urbanístico de Toledo a inicios de siglo, el proceso de elaboración del POM, sus objetivos y la modificación clave entre el documento inicial de 2005 y el aprobado en 2007. Se analiza el planeamiento desarrollista que se pretendía aplicar en Toledo. Se estudian los problemas judiciales del POM. Se detalla como la crisis paralizó su ejecución. Se hace la propuesta de un planeamiento urbanístico diferente para la ciudad. Finalmente, se acaba el trabajo con una breve discusión y una conclusión.

La metodología empleada se inicia con el planteamiento de la pregunta clave de la investigación. A continuación, se pasó a una fase de exploración con recolección de informaciones a través del trabajo bibliográfico. Se acude tanto a bibliografía general sobre el urbanismo, como a obras centradas en España y, sobre todo, a los estudios académicos precedentes sobre Toledo. Después, se utilizan múltiples fuentes para logar los objetivos señalados: estadísticas demográficas y de vivienda; datos sobre el proceso de urbanización de la ciudad a través del estudio de los sectores residenciales

${ }^{2}$ El propio Zárate (2016, p. 723) alude de una forma incidental a esta dinámica en una reciente investigación centrada en los paisajes culturales, en su conservación y valorización turística. 
de España de 2014 del Ministerio de Fomento; el buscador de jurisprudencia del Consejo General del Poder Judicial; el Sistema de Información Urbana (SIU) del Ministerio de Fomento; noticias de prensa y el propio POM de 2007. Posteriormente, se visualizan y se sintetizan las informaciones y datos recolectados con herramientas informáticas, como el SIG, utilizando el programa QGIS. De manera inmediata, se interpretan y analizan de manera cuantitativa y cualitativa. De esta forma, se obtienen los resultados y, por deducción, las conclusiones del trabajo.

La finalidad principal de este artículo es hacer una contribución a los estudios urbanísticos de las ciudades españolas a través del ejemplo de Toledo. Se trata también de actualizar los precedentes bibliográficos sobre la ciudad tras una convulsa etapa. Desde el punto de vista práctico, planteamos un modelo territorial distinto, un urbanismo menos expansivo y más social y participativo. Las propuestas pueden ser aplicadas en otros muchos núcleos con un fuerte potencial residencial en su planeamiento vigente. Se considera que la crisis de 2008 debe suponer un punto de inflexión en la ordenación urbana de España.

\section{Resultados}

\subsection{Elección del modelo urbano desarrollista y ¿̇su actual final?}

Las ciudades son sistemas complejos e inconclusos, en esta inconclusión reside la posibilidad de hacer: hacer la historia, hacer la sociedad, hacer la política y hacer el urbanismo (Sassen, 2014, p. 15). Con respecto al urbanismo, la mayoría de los núcleos urbanos contemporáneos han propiciado un crecimiento expansivo. La urbanización se extiende ampliamente por el territorio ${ }^{3}$. Se han producido grandes áreas compuestas por unidades urbanas homogéneas internamente. El resultado es una clara zonificación formal y funcional. Un ritmo de crecimiento urbano rápido que produce una ciudad difusa o ciudad red (Rullán, 2003, p. 167).

El proceso de urbanización contemporáneo de Toledo se corresponde con este modelo de crecimiento expansivo, zonificado y difuso. Ha originado una exagerada separación entre sus unidades urbanas con múltiples y amplios espacios intersticiales entre ellas (Figura 1). Es la consecuencia de una ausencia de una idea racional de ciudad que dirigiese las pautas de este desarrollo. Esta circunstancia ha permitido la creación de ámbitos urbanizados muy distantes entre sí. Esto plantea claros problemas de conectividad y una complicación para la movilidad ciudadana.

Sainz (1999) realiza un ejercicio de síntesis y de generalización en su estudio sobre el arquitecto y urbanista italiano Aldo Rossi. Así, afirma que ha habido tres ideas guías o paradigmas urbanos de la modernidad en aquellos núcleos que contaban

\footnotetext{
${ }^{3}$ Una profunda comprensión teórica se obtiene con la lectura de la obra de Lois, González y Escudero (2012).
} 
con un origen preindustrial previo. Se trata de la idea de descentralización, la de la continuidad y la de innovación respecto a la estructura heredada del pasado (Sainz, 1999, p. 78). A cada uno de estos paradigmas urbanos le correspondería un concepto de ciudad. Con la idea guía de la descentralización la urbe se entiende como un organismo natural. Con la de continuidad se identifica como un artefacto cultural y con la de la innovación como una máquina urbana. Toledo tiene un centro histórico de 114,9 hectáreas (Ministerio de Fomento, 2017). Ha sido su espacio residencial casi único hasta la mitad del siglo XX. A partir de entonces, ha aplicado los tres indicados paradigmas en su urbanización contemporánea. Sus diferentes planificaciones lo han hecho sectorialmente: la idea de continuidad en su casco antiguo ${ }^{4}$ y la de descentralización e innovación en su crecimiento más reciente.

Figura 1. Clases de suelo del municipio de Toledo.

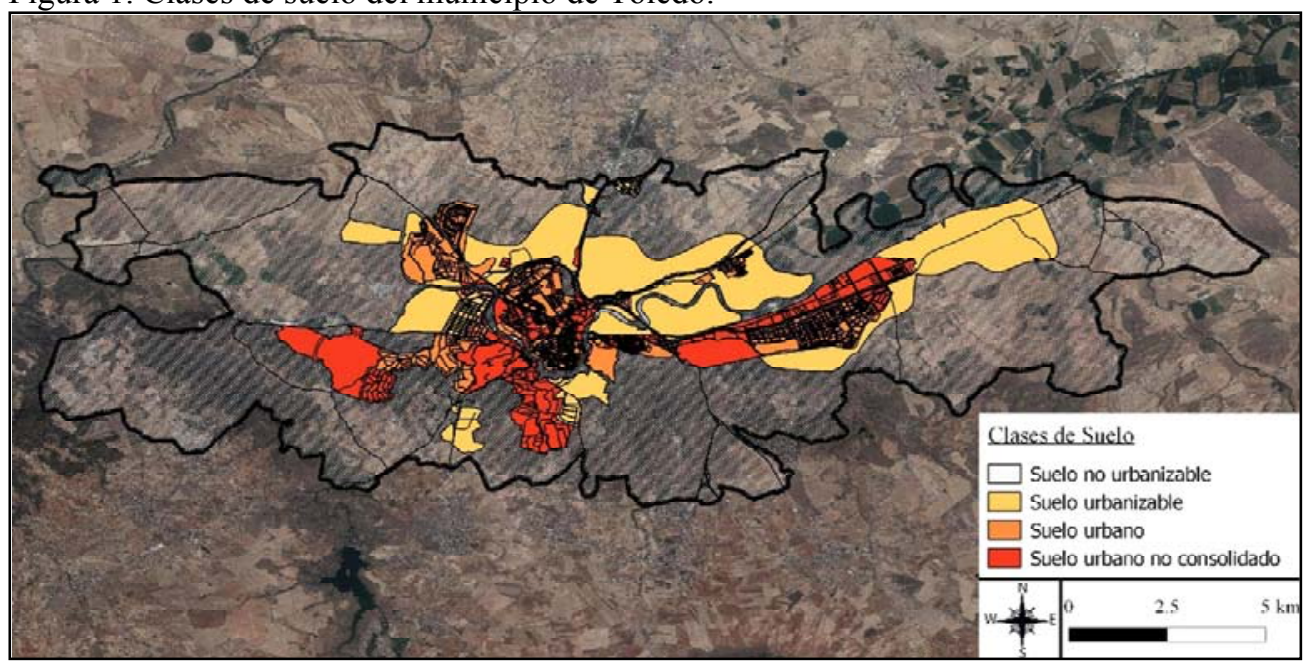

Fuente: Elaboración propia, a partir de SIU (Ministerio de Fomento, 2017), ortofoto del PNOA y Cartociudad (CNIG, 2017).

La capital toledana ha carecido de una idea de ciudad sólida. No ha aplicado la fórmula intermedia entre crecimiento y conservación que recomendaba Lynch (1985). El urbanista estadunidense indicaba que una ciudad debería tener un ritmo de crecimiento moderado óptimo para que hubiese una buena integración, inteligibilidad y acceso social. Son principios todos ellos ausentes en Toledo. La ciudad ha optado

\footnotetext{
${ }^{4}$ El primer plan de Toledo se aprueba en 1940 para proteger al centro histórico de la ciudad, declarado como Monumento Nacional. En 1997 entra en vigor Plan Especial del Centro Histórico (PECHT) para la salvaguarda de ese singular espacio (Tomé, 2007, p. 79).
} 
por un modelo de crecimiento urbanístico continuo y expansivo fuera de su centro histórico. La mayoría de las ciudades españolas han hecho lo mismo (López de Lucio, 1993). Esta idea de urbanismo desarrollista sigue en casi todos los planes de ordenación urbana vigentes (Ministerio de Fomento, 2014).

Sin embargo, el crecimiento urbano continuo y expansivo se paralizó en el año 2008 en España. Fue el estallido de la burbuja inmobiliaria que se había ido creando durante una década. Con ello, se produjo la detonación de una profunda crisis económica dado el gran peso que el sector inmobiliario había alcanzado en el PIB, en el empleo directo e indirecto, en el endeudamiento familiar y empresarial y en el balance de las instituciones financieras (Burriel, 2014, p. 101). Los indicadores económicos parecen señalar una incipiente recuperación en el presente. No obstante, Burriel (2014) demuestra que no es una crisis constructiva periódica sino el inicio de una nueva situación. Esto exige repensar el modelo urbanístico actual desde el punto de vista territorial, del planeamiento urbano y del sistema de producción de ciudad. A pesar de ello, los planes vigentes de muchas ciudades están pensados para un enorme desarrollo edificatorio y demográfico previsto antes de la crisis. Se basan en un escenario muy diferente del presente y del previsible a medio plazo. Se analizará esta cuestión en la ciudad de Toledo

\subsection{El fracaso del planeamiento urbanístico toledano actual.}

\subsubsection{El contexto urbanístico de Toledo a inicios de siglo, el proceso de elaboración del POM, sus objetivos principales y el «salto adelante» de 2005 a 2007.}

Toledo ha tenido una sucesión de planes urbanos. Su gran punto en común ha sido optar siempre por un crecimiento continuo. Esto se ha realizado de manera desvertebrada. No se ha contado con una idea de ciudad clara y estructurada. Se trata de una urbe fallida donde ya se han completado tres planteamientos con ámbito general de 24, 22 y 21 años de vigencia: el de 1940-43, 1964 y 1986, que han resultado ser estrategias urbanísticas muy desacertadas. El plan anterior al POM de 2007 es el Plan General de Ordenación Urbana aprobado en 1986. Se trata de una figura urbanística clave con múltiples modificaciones a lo largo de este tiempo. Aunque su memoria justificativa (Foro GTT y Orbe, 1986) incide en la necesidad de una planificación estructurada y lógica que dirigiese el modelo de crecimiento, no fue capaz de articular entre sí los sectores urbanos existentes. Permitirá el principal desarrollo de la ciudad durante dos décadas. Este PGOU calificó como urbanizable grandes extensiones de suelo. Se siguió una lógica desarrollista y especulativa donde el sector constructivo, financiero e inmobiliario fueron los beneficiados. No se tuvo en cuenta ni un plan temporal de ejecución de las nuevas actuaciones, que fueron desarrollándose azarosamente a lo largo del tiempo a través de múltiples planes parciales, ni una estructura lógica de la ciudad (Campos y Escudero, 2007). Por el contrario, permitió una enorme dispersión con urbanizaciones en sectores tan alejados 
como Azucaica en el este o Montesión en el oeste, por ejemplo. Da pie a un gran crecimiento expansivo periurbano de la ciudad.

La memoria del POM de 2007 afirma que la necesidad de desarrollar un nuevo Plan de Ordenación Municipal se apoya (...) en la evolución de la ciudad y sus demandas en el transcurso de los últimos 21 años (...) y se plantea con creciente urgencia la necesidad de abordar diferentes déficit urbanisticos (...) que no es posible resolver satisfactoriamente con el plan vigente, ni recurriendo a modificaciones puntuales del mismo (Ayuntamiento de Toledo, 2008, p. 7). De hecho, el plan de 1986 y todas las modificaciones que había sufrido habían dado lugar a un modelo de ciudad desarticulada y desvertebrada que era necesario recomponer. Muelas y Parrilla (2008, p. 41) señalan que el PGOU de 1986 estaba agotado, superado ya su marco temporal y desarrollo; ni podía abordar nuevas demandas ni dar solución a los problemas urbanos de la ciudad, a un Toledo fragmentado y débilmente articulado. Estos autores destacan como problemas clave en la situación urbanística de Toledo de 2000 la carencia de un sistema estructurante equilibrado de centralidades, la desarticulación entre tejidos urbanos, la insuficiencia y congestión de la red viaria y la oferta del suelo escasa e inadecuada (Muelas y Parrilla, 2008, pp. 41-43).

En base a este problemática situación urbanística de la ciudad se desarrollan los objetivos y estrategias estructurales del POM: 1. Diseñar una ciudad unitaria y cohesionada, integrando las partes en el todo y mejorando los sistemas estructurantes, para ello se plantea proyectar nuevos crecimientos para llenar los vacíos del discontinuo urbano, fortalecer la red de conexiones existentes y mejorar la movilidad, articular un sistema de espacios libres y dotacionales, crear una red de áreas de centralidad adecuada a las demandas sociales de los distintos barrios, hacer una oferta de suelo para áreas de actividades económicas y empleo, diseñar un modelo de ciudad de usos equilibrado y sostenible, promover un adecuado modelo de poblamiento y de tipologías urbanas y mejorar el metabolismo urbano; y 2. Compatibilizar modernidad y monumentalidad mediante la coherencia entre desarrollo y conservación, la preservación del patrimonio monumental, paisajístico y cultural y entender el turismo como valor central de Toledo como ciudad monumental (Muelas y Parrilla, 2008, pp. 43-50 y con un mayor desarrollo el apartado 2. Modelo Territorial y Urbanístico de la memoria justificativa del POM, Ayuntamiento de Toledo, 2008, pp. 31-77). En rasgos generales, no es la lógica y oportunidad de estos objetivos y estrategias los que plantean problemas, sino establecer la clasificación del suelo como determinación fundamental (Ayuntamiento de Toledo, 2008, p. 79) y plantear, finalmente, un modelo extremadamente desarrollista como veremos en el apartado 2.2.2.

La redacción del nuevo POM fue encomendada a la empresa AUIA en el año 2000 (Muelas y Parrilla, 2008, p. 34). En 2001 se elaboró un documento previo con el estado actual de la cuestión. En 2003 se hizo un diagnóstico urbano con un análisis pormenorizado de los barrios y unidades urbanísticas existentes y un documento de bases, criterios y objetivos del POM. En 2004 se realizó un documento de avance para la concertación interadministrativa enviado a diferentes organismos públicos y que se expuso y divulgo públicamente. En 2005 se redactó y se expuso el documento 
de información pública (Muelas y Parrilla, 2008, pp. 36-40 -estos autores explican pormenorizadamente las diferentes etapas del proceso de elaboración del POM). Tras la recepción de las alegaciones y de los informes de concertación de distintas administraciones y organismos implicados, el plan se adapta a los cambios surgidos (Muelas y Parrilla, 2008, p. 39). Con su aprobación en 2007, el POM finalizaba un proceso largo y abierto con el resultado aparente de un amplio consenso ciudadano y político. Es la afirmación de Muelas y Parrilla (2008, p. 40), que muy pronto demostrará su fragilidad, como se verá en el apartado 2.2.3.

El tránsito de la propuesta de 2005 a la aprobación definitiva de 2007 es un momento clave para entender el fracaso de este planeamiento. El POM recibió un total final de 163 alegaciones de individuos, asociaciones y empresas y 35 informes de administraciones y organismos relativos al documento de información pública de 2005 (Ayuntamiento de Toledo, 2008, pp. 11-15). Con las alegaciones y los informes se adoptaron los cambios «necesarios» (Muelas y Parrilla, 2008, p. 39 -las comillas angulares no son de la cita original, se añaden ahora). Es el hecho que la memoria justificativa resuelve simplemente con la frase introducción de las modificaciones que (el Ayuntamiento) ha estimado oportunas (Ayuntamiento de Toledo, 2008, p. 10). La injerencia política va a dar un giro importante al planeamiento urbanístico inicial. El número de viviendas nuevas proyectadas se incrementará en un $32 \%$ en el POM aprobado en 2007 en comparación con el sometido a información pública de 2005 (pasan de 37.082, que ya era un elevado número, a 49.258), la superficie edificable en un $48 \%$ (de $7.297 .046 \mathrm{~m}^{2}$ a $11.186 .076 \mathrm{~m}^{2}$ ), la superficie construible industrial en un $243 \%$, la previsión del consumo de agua en un $86 \%$, la de desagüe para aguas fecales en un $89 \%$ y la de la demanda de energía eléctrica hasta un 536\% (Sentencia 573/2011, CENDOJ, 2016). Se había producido un gran «salto adelante» en el desarrollo urbanístico previsto. Una modificación difícil de casar con los objetivos y estrategias que la propia memoria justificativa del POM señala. Una alteración que dará pie a los problemas judiciales del plan analizados en el apartado 2.2.3.

\subsubsection{Un planeamiento urbano muy desarrollista.}

El futuro de la ciudad de Toledo se sigue planteando bajo la fórmula del planeamiento urbanístico. El POM de 2007 aplica una lógica desarrollista. Surge, además de por la desestructuración de la ciudad, por el agotamiento del suelo programado para urbanizar por el Plan General de 1986. Un hecho que es entendido como un obstáculo para el crecimiento de Toledo. Plantea particularmente la disponibilidad de Suelos Urbanizables para los diferentes usos y especialmente el residencial (Ayuntamiento de Toledo, 2008, p. 7). También especifica que se ha de crear una oferta adecuada de suelo y que el suelo residencial es elemento central de Plan (Ayuntamiento de Toledo, 2008 , p. 33). En definitiva, el nuevo plan sigue la lógica urbanística desarrollista anterior. Se entiende que planificar es principalmente calificar nuevo suelo urbanizable.

La redacción del POM fue dirigida por el fallecido arquitecto y urbanista Mario Muelas. Nacido en Cuenca, formado en Madrid y con múltiples intervenciones 
previas en las ciudad toledana desde la década de 1980 (Sánchez, 2015). Se elabora bajo una perspectiva urbanista procedente del área metropolitana de Madrid. Se redacta durante el periodo principal del boom inmobiliario en España. En Toledo, la variación de superficies artificiales fue del $25,6 \%$ entre el año 2000 y 2006, (Ministerio de Fomento, 2017).

Figura 2. Clases de suelo (urbano, consolidado o no, y urbanizable delimitado) de la ciudad de Toledo.

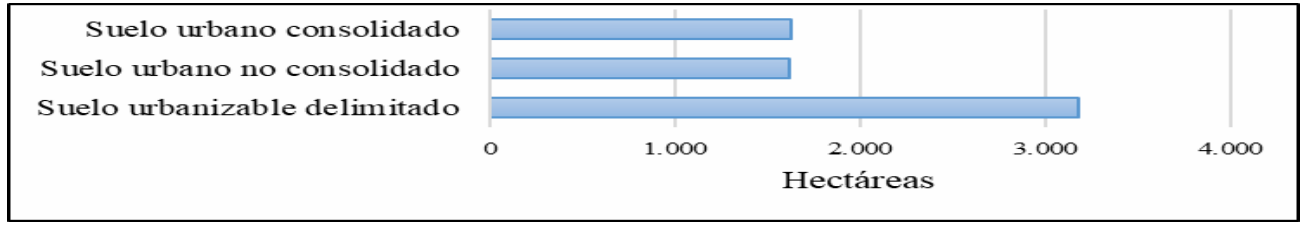

Fuente: Elaboración propia, a partir de SIU (Ministerio de Fomento, 2017).

Este peculiar contexto prourbanizador se refleja en los escritos del propio Muelas. El arquitecto señala que la oferta del suelo en Toledo era escasa y que esto generaba un problema de rigidez en el suelo urbanizable residencial y, como consecuencia de ello, habia una baja oferta de vivienda de calidad y de precios intermedios (Muelas y Parrilla, 2008, p. 43). Es la conocida teoría de que es necesario flexibilizar el mercado del suelo aumentando la calificación del mismo como urbanizable (Parada, 1999, p. 89) para bajar los precios de las viviendas y hacerlas más accesibles. En 1964, el arquitecto alemán Ulrich Von Altenstadt ya afirmaba que los verdaderos beneficiarios de este tipo de política del suelo son los que especulan con el mismo (en Mistercherlich, 1977, p. 58). Es el resultado de la falacia de aplicar los principios de la demanda y la oferta de la economía ortodoxa a una mercancía ficticia, sin costes de producción, como es el suelo. Esto acaba produciendo el efecto contrario del que se dice buscar (López y Rodríguez, 2010, p. 310). García (2000) lo demuestra para Valladolid y Ponce (2006) para la Comunidad Valenciana.

En Toledo, el PGOU de 1986 se posicionaba como solución a la falta de disponibilidad de suelo urbanizable que había en la ciudad, lo cual había originado un encarecimiento del mismo (Castro, 1986). No lo logró. El POM de 2007 denuncia que ese plan anterior dio lugar a que el suelo fuese excesivamente caro. La solución que se propone ahora vuelve a ser calificar más. Actualmente (Figura 2), Toledo tiene más suelo urbanizable delimitado que suelo urbano, consolidado o no. La calificación de suelo urbanizable para nueva vivienda es un objetivo principal del POM de Toledo. Se enmascara mediante un propósito de integrar de manera sostenible las partes de la ciudad mediante el relleno de los vacíos del discontinuo urbano. Sin embargo, el plan acaba planteando la ampliación de la ciudad y no la cohesión de la existente. De hecho, los problemas estructurales de la ciudad se ven más agravados que resueltos con el POM (Zárate, 2007, p. 151). Los principios de la sostenibilidad se quedan relegados a la exposición de motivos. Aparecen en los objetivos y estrategias del POM. No están en el articulado. El plan califica más suelo urbanizable y más superfi- 
cie edificable total que el suelo urbano existente (Zárate, 2007, p. 157, Muelas y Parrillas, 2008, p. 47 y Ministerio de Fomento, 2014, p. 7). El municipio de Toledo tiene 231,78 $\mathrm{km}^{2}$. El 7,04\% es superficie urbana consolidada en 2010 (Ministerio de Fomento, 2017). El POM delimita nuevos sectores residenciales (Tabla 1) que se corresponden con el $20,72 \%$ de la extensión municipal.

Tabla 1. Principales desarrollos residenciales pendientes de edificar en Toledo.

\begin{tabular}{|c|c|c|c|c|c|c|c|}
\hline $\begin{array}{c}\text { NOMBRE } \\
\text { DEL SECTOR }\end{array}$ & Situación & Superficie $\left(\mathrm{m}^{2}\right)$ & $\begin{array}{c}\text { Edifica- } \\
\text { bilidad (m2) }\end{array}$ & $\begin{array}{l}\text { Grado de } \\
\text { Urbani- } \\
\text { zación } \\
(\%)\end{array}$ & $\begin{array}{c}\text { Grado } \\
\text { de } \\
\text { Edifi- } \\
\text { cación } \\
(\%)\end{array}$ & $\begin{array}{l}\mathrm{N}^{\mathrm{o}} \text { de } \\
\text { viviendas } \\
\text { previsto }\end{array}$ & $\begin{array}{l}\mathrm{N}^{o} \text { de } \\
\text { vivien- } \\
\text { das pen- } \\
\text { dientes }\end{array}$ \\
\hline $\begin{array}{c}\text { Carrasco-Dehesa de } \\
\text { Buenavista }\end{array}$ & $\begin{array}{l}\text { Crecimiento } \\
\text { septentrional }\end{array}$ & 3.411 .803 & 1.293 .796 & 0 & 0 & 8.558 & 8.558 \\
\hline Pinedo-Valdecubas 2 & $\begin{array}{l}\text { Crecimiento } \\
\text { septentrional }\end{array}$ & 3.110 .034 & 907.640 & 0 & 0 & 5.910 & 5.910 \\
\hline $\begin{array}{c}\text { Ampliación del } \\
\text { polígono residencial de } \\
\text { Santa } \mathrm{M}^{\mathrm{a}} \text { de Benqueren- } \\
\text { cia }\end{array}$ & Polígono-Este & 1.246 .686 & 489.691 & 0 & 0 & 3.020 & 3.020 \\
\hline $\begin{array}{c}\text { Fase este B del polígono } \\
\text { de Santa } \mathrm{M}^{\mathrm{a}} \text { de } \\
\text { Benquerencia } \\
\end{array}$ & Polígono-Este & 394.258 & 144.652 & 100 & 0 & 1.448 & 1.448 \\
\hline Ramabujas & Polígono-Este & 1.181 .487 & 471.754 & 0 & 0 & 2.861 & 2.861 \\
\hline Valdecubas & Polígono-Este & 2.128 .488 & 911.939 & 0 & 0 & 5.770 & 5.770 \\
\hline Azucaica & Vega Alta-Este & 2.378 .064 & 902.787 & 0 & 0 & 5.972 & 5.972 \\
\hline Huerta del Rey & Vega Alta-Este & 821.141 & 279.108 & 0 & 0 & 2.052 & 2.051 \\
\hline La Alberquilla Este & Vega Alta-Este & 1.184 .794 & 497.188 & 0 & 0 & 2.948 & 2.948 \\
\hline La Alberquilla Oeste & Vega Alta-Este & 1.119 .443 & 457.529 & 0 & 0 & 2.782 & 2.782 \\
\hline La Peña-Azucaica & Vega Alta-Este & 742.935 & 309.925 & 0 & 0 & 1.843 & 1.843 \\
\hline Peraleda & Vega Baja-Oeste & 1.003 .826 & 431.669 & 25,4 & 0,2 & 2.662 & 2.657 \\
\hline San Bernardo & Vega Baja-Oeste & 1.704 .637 & 403.750 & 0 & 0 & 2.044 & 2.044 \\
\hline \multirow[t]{2}{*}{ Vega Baja 1} & Vega Baja-Oeste & 391.041 & 222.209 & 31,5 & 1,2 & 1.300 & 1.285 \\
\hline & Totales & 20.818 .637 & 7.723 .637 & 3,71 & 0,04 & $49.170^{5}$ & 49.149 \\
\hline
\end{tabular}

Fuente: Elaboración propia, a partir de Ministerio de Fomento, 2014, p. 580.

El POM responde ante todo a prácticas especulativas. Beneficia fundamentalmente a los propietarios del suelo y promotores inmobiliarios, pero no al conjunto de los ciudadanos (Zárate, 2007, p. 159). No hay un modelo de ciudad que haga a Toledo

${ }^{5}$ En este total sólo se recogen los sectores de suelo con desarrollos previstos de más de 1.000 viviendas, de ahí que no coincida con el que da el Tribunal Superior de Justicia de Castilla-La Mancha de 49.258 viviendas previstas por el POM de 2007 (CENDOJ, 2016). 
crecer equilibrada y armónicamente (como pedía López en 2005, p. 342). Se planifica un explosivo crecimiento de la ciudad (Figura 3).

Figura 1. Planes parciales en suelo urbanizable del POM de Toledo de 2007.

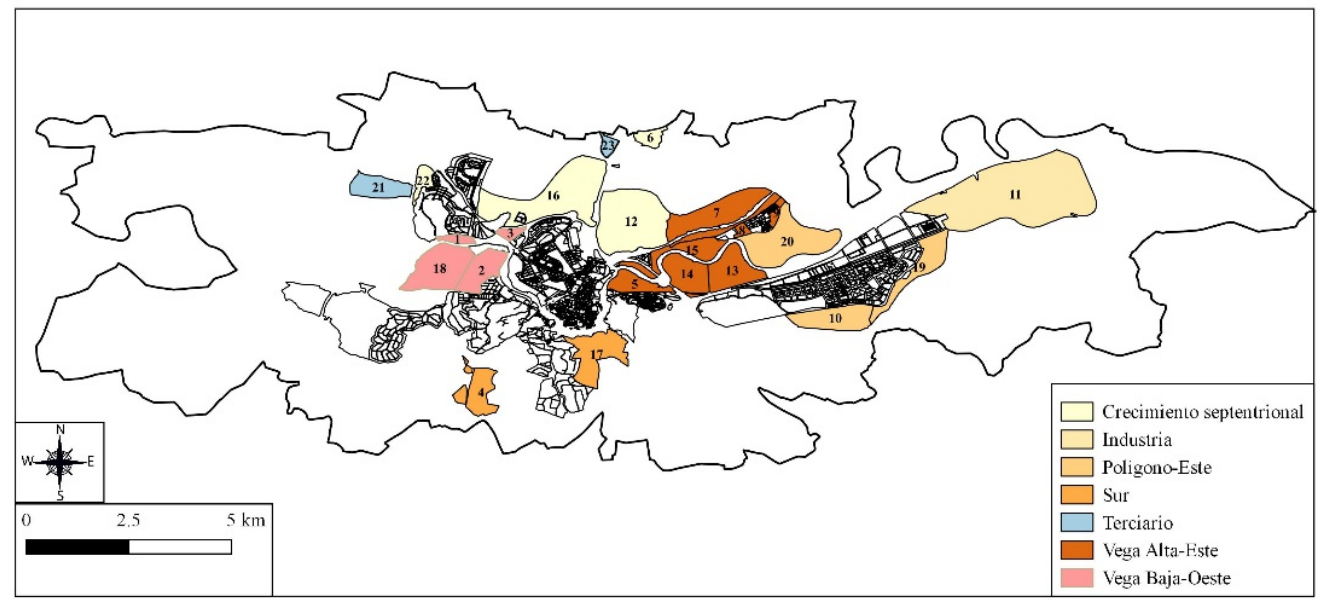

Fuente: Elaboración propia, a partir del POM (Ayuntamiento de Toledo, 2008) y Cartociudad (CNIG, 2017).

Así, son creados múltiples nuevos sectores urbanos dispersos: en la Vega Baja ${ }^{6}$, al oeste del municipio; en la Vega Alta, en la parte oriental, con una gran intensidad; en una nueva ampliación del polígono residencial de Santa María de Benquerencia ${ }^{7}$ al este y en un fuerte crecimiento septentrional (Tabla 1 y Figura $3^{8}$ ). Además, el POM califica áreas destinadas a bajas densidades de vivienda. Se trata de urbanizaciones unifamiliares en sectores periféricos del municipio. Supone un impulso a la

${ }^{6}$ El río Tajo tiene dos grandes llanuras aluviales en el municipio de Toledo. Popularmente se conocen como Vega Baja, aguas abajo del centro histórico, y Vega Alta, aguas arriba. En medio, el río se encaja en un torno sobre el que sobresale el peñón donde se localiza el casco antiguo (Lorente y Vázquez, 2006, p.113), formando un paisaje cultural excepcional.

${ }^{7}$ Se construye en la década de 1960, dentro de un plan estatal para descongestionar manufactura y poblacionalmente la capital del Estado. Está situado a 8 kilómetros al este del centro histórico. Hoy es el barrio más poblado de Toledo con 21.235 habitantes, el 21,5\% de los residentes en la ciudad (Ayuntamiento de Toledo, 2016)

${ }^{8}$ La correspondencia de los números de los planes parciales de la figura es la siguiente: 1. Huerta del Pavón, 2. Peraleda, 3. Buenavista-Observatorio, 4. Regulación parcelación ilegal Cerro de los Palos, 5. Huerta del Rey, Galiana y Estación AVE, 6. El Beato, 7. Valdecubas, 8. Azucaica Sur, 9. Azucaica Este, 10. Ampliación polígono residencial, 11. Ampliación polígono industrial, 12. Pinedo, 13. La Alberquilla Este, 14. La Alberquilla Oeste, 15. La Peña-Azucaica, 16. Buenavista-Carrasco, 17. La Sisla, 18. San Bernardo, 19. Ramabujas, 20. Azucaica-Polígono, 21. Parque terciario empresarial La Legua Este, 22. La Legua Este y 23. La Abadía. 
periurbanización de Toledo tanto dirección sur (La Sisla), como al norte (en El Beato y La Legua), al oeste (en la Huerta del Pavón y San Bernardo) y al este (en Valdecubas).

El resultado final es que Toledo es el municipio urbano de España con mayor potencialidad residencial, tras los de Madrid y Murcia (Ministerio de Fomento, 2014, p. 28).

\subsubsection{Un planeamiento urbano con un accidentado periplo judicial.}

El POM de Toledo se inicia en 2000 y se aprueba definitivamente en 2007. Ha tenido un difícil recorrido administrativo y legal hasta el presente. En primer lugar, lo tuvo en su aprobación. Inicialmente, un documento con importantes cambios con respecto al modelo original de 2005, como se explicó, fue refrendado en mayo de 2006 por el Ayuntamiento de Toledo. Fue enviado en junio de 2006 a la Consejería de Vivienda y Urbanismo de la Junta de Comunidades de Castilla-La Mancha (JCCM). Esta es la encargada de su aprobación definitiva según la legislación autonómica vigente ${ }^{9}$. La JCCM ordenó hacer una serie de modificaciones que el gobierno municipal realiza y aprueba el 23 de marzo de 2007. Tres días después, el 26 de marzo de 2007, la Consejería también da su visto bueno y el POM entraba en vigor.

Las diversas e importantes alteraciones introducidas con respecto al documento de 2005 darán lugar a un largo itinerario judicial del plan toledano. Unas modificaciones tan significativas exigían abrir un nuevo trámite de información pública según la legislación estatal básica de urbanismo ${ }^{10}$. No se hizo. Son interpuestos una serie de recursos contra el POM.

El Tribunal Superior de Justicia de Castilla-La Mancha (TSJCLM) emite un conjunto de sentencias ${ }^{11}$ que atienden a estas demandas y anulan reiteradamente el POM. La causa es no haber realizado información pública del POM modificado. Entre estos dictámenes, resulta interesante referirse particularmente al 573/2011. Se trata del que estima el recurso contencioso-administrativo contra la aprobación del POM que había formulado la Asociación Castellano-Manchega para la Defensa del Patrimonio Natural (ACMADEN-Ecologistas en Acción). Es un ejemplo de como la presión social es fundamental para poder poner a salvo valores patrimoniales, paisajísticos y medioambientales amenazados (Zárate, 2007, p. 173). Anteriormente (Figura 4), ya había habido un movimiento ciudadano claramente contrario al POM,

\footnotetext{
${ }^{9}$ La TRLOTAU (Texto Refundido de la Ley de Ordenación del Territorio y de la Actividad Urbanística), entonces la Ley 7/2005 y hoy la Ley 1/2010, su última modificación

${ }^{10}$ La Ley 6/1998 sobre Régimen del Suelo y Valoraciones, vigente hasta el 01 de julio de 2007, consecuentemente en el momento en que se aprobó el POM.

11 Sentencias 451/2011, 452/2011, 516/2011 y 570/2011, que responden a recursos de particulares; 562/2011, al de la empresa de promoción inmobiliaria Miratorre S.A.; 573/2011, explicada en el texto; y 591/2011, al de un particular y dos empresas relacionadas con actividades inmobiliarias, Inversiones Doacla S.L. y Galafre 21 S.L. (CENDOJ, 2016)
} 
así como de diferentes asociaciones como la Real Sociedad Geográfica (Bosque y Zárate, 2006). Los colectivos sociales pueden tener capacidad de respuesta y de denuncia ante una legislación urbanística permisiva, como es la TRLOTAU (Pais, 2004, p. 333). Pueden enfrentarse a una orientación política local centrada en el crecimiento urbanístico sin fin, como sucedió con el POM en Toledo.

Figura 4. Caricatura para la movilización ciudadana frente al POM de Toledo.

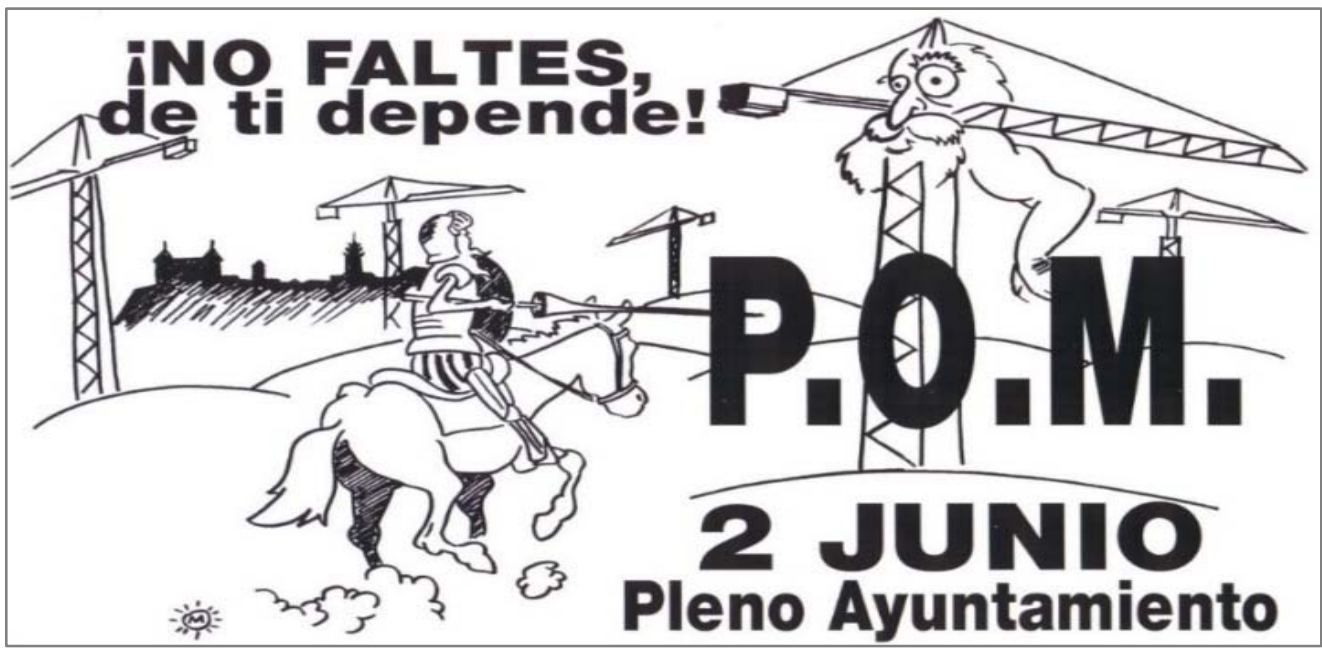

Fuente: Anónima.

El Ayuntamiento de Toledo no llegó nunca a anular el POM a pesar de los múltiples dictámenes del TSJCLM. Decidió hacer un recurso de casación al Tribunal Supremo. También lo interpuso la JCCM, pero no fue admitido a trámite. El gobierno municipal consideraba que la TRLOTAU solo exige un único periodo de información pública. Afirmaba que el TSJCLM aplicó erróneamente la legislación estatal sobre la comunitaria. Estamos ante el complicado asunto legal en España de delimitar hasta dónde llegan las competencias nacionales y hasta dónde las autonómicas en materia de urbanismo. Finalmente, el Tribunal Supremo confirmó la anulación del POM en sentencia de 27 de febrero de 2014 (CENDOJ, 2016). La causa vuelve a ser no haber sacado el documento a información pública tras sus modificaciones.

Al Ayuntamiento de Toledo aún le quedaba la posibilidad de acudir al Tribunal Constitucional. Podía alegar el conflicto entre las legislaciones estatal y autonómica y así lo hizo. Una primera sentencia en septiembre de 2015 y tres más en junio de 2016 (Objetivo Castilla-La Mancha, 2016) concedieron el amparo al Ayuntamiento de Toledo. Sin embargo, el Tribunal Constitucional también emite en febrero de 2017 una sentencia por la cual anula el artículo de la TRLOTAU que reconocía que no era necesario someter a una segunda información pública los documentos de un plan de ordenación municipal (Europa Press, 2017). Estimaba así una cuestión de 
inconstitucionalidad presentada por el TSJCLM. Dos meses después, en abril de 2017, el TSJCLM se vuelve a pronunciar sobre el POM para declararlo anulable y pedir al Ayuntamiento que lo vuelva a sacar a información pública (Bachiller, 2017). Esta nueva sentencia dejaba finiquitado el POM de 2007, pero el Ayuntamiento intentó un recurso de casación en mayo de 2017 (El Digital de Castilla-La Mancha, 2017) que fue inadmitido en el mes de noviembre (Bachiller, 2017b). Aun así, el gobierno local toledano decide alargar la vía judicial y promover un incidente de nulidad de actuaciones ante el Tribunal Supremo (La Tribuna de Toledo, 2017)

Hoy, el municipio de Toledo mantiene válido el POM de 2007 tras una larga lucha judicial para conseguirlo. No obstante, el gobierno municipal afirma en los medios de comunicación que está trabajando en un nuevo POM (Europa Press, 2015b). El Consistorio asegura que será más ajustado a las verdaderas necesidades de la ciudad, tanto en el número de viviendas como en desarrollo industrial, servicios, sostenibilidad e integración (Objetivo Castilla-La Mancha, 2016). Es difícil entender cómo se puede luchar judicialmente con tanto ahínco por mantener activo un POM al tiempo que se reconoce que no responde a las necesidades reales del municipio y se trabaja en otro. La única manera de hacerlo es desde el ambiguo ámbito de la política local. Desde luego, no se puede hacer desde la racionalidad del urbanismo.

En cualquier caso, el POM de Toledo de 2007 está vigente, aunque muy probablemente ya por muy poco tiempo más. Califica una amplia extensión de suelo urbanizable y un futuro de miles de viviendas nuevas. Lo mismo sucede en otras múltiples ciudades españolas que tienen aún un planeamiento urbano desarrollista (Ministerio de Fomento, 2014). El POM de Toledo, y los planes similares, son, expresándolo de forma gráfica y metafórica, «bombas de relojería». Permitirían en el tiempo realizar legalmente todo lo que tienen planificado. Posibilitan así perpetuar el modelo de crecimiento constructivo en cuanto fuera posible en los próximos años. Es decir, tan pronto como una nueva coyuntura económica lo permitiese fácilmente se podría retornar desde el punto de vista legal a las estrategias que llevaron al boom inmobiliario. El suelo está calificado y las nuevas unidades urbanísticas dibujadas en el plano de Toledo disponibles para su ejecución. Algunos líderes políticos locales, preocupados por la situación legal del POM, dejan claro que es eso precisamente lo que desean: la edificación de lo planificado ${ }^{12}$. Es la idea, extendida desde el último cuarto del siglo XX, tras la crisis del petróleo, de que el crecimiento urbano es uno de los factores que puede dinamizar la economía, y lejos de ser algo a controlar pasa a ser algo que hay que fomentar a toda costa (García, 2004, p. 15).

\subsubsection{Un planeamiento sobre el papel no ejecutada por la crisis.}

\footnotetext{
${ }^{12}$ Así se expresaba el portavoz del Grupo Municipal Popular, Jesús Labrador: nadie va a venir a hacer inversiones en Toledo bajo las sospechas de que las actuaciones que haga puedan ser declaradas nulas porque el instrumento sobre el que se sostiene no es válido (Europa Press, 2015a).
} 
La profunda crisis económica, y, en concreto, de los sectores constructivo, financiero ${ }^{13}$ e inmobiliario, tiene la misma fecha de nacimiento que el POM de Toledo. Sus primeros síntomas son de 2007 para estallar con clara virulencia en 2008, cuando se paraliza la actividad inmobiliaria en España. Por esta razón, no hubo ni desarrollo ni ejecución de la mayoría de lo planificado en el POM toledano. El suelo calificado como urbanizable simplemente permanece como tal (de forma ocurrente Zárate (2016, p. 723) habla de «barbecho urbano). Así, de las viviendas previstas solo se ha construido el 1,7\%. El 83,4\% de las áreas de suelo de desarrollo ni tan siquiera ha iniciado su urbanización (Ministerio de Fomento, 2014, p. 570). Otro significativo dato, en el estudio de los Sectores Residenciales en España (Ministerio de Fomento, 2014 , p. 570) se señala la realidad que se percibe paseando por la ciudad: no había ni una sola hectárea en proceso de edificación en ese momento. El proceso de construcción residencial en Toledo está detenido. La programación y las prioridades de desarrollo (Figura 5) diseñadas en el POM no se han cumplido.

Figura 5. Prioridades de desarrollo de los planes parciales en suelo urbanizable del POM de Toledo de 2007.

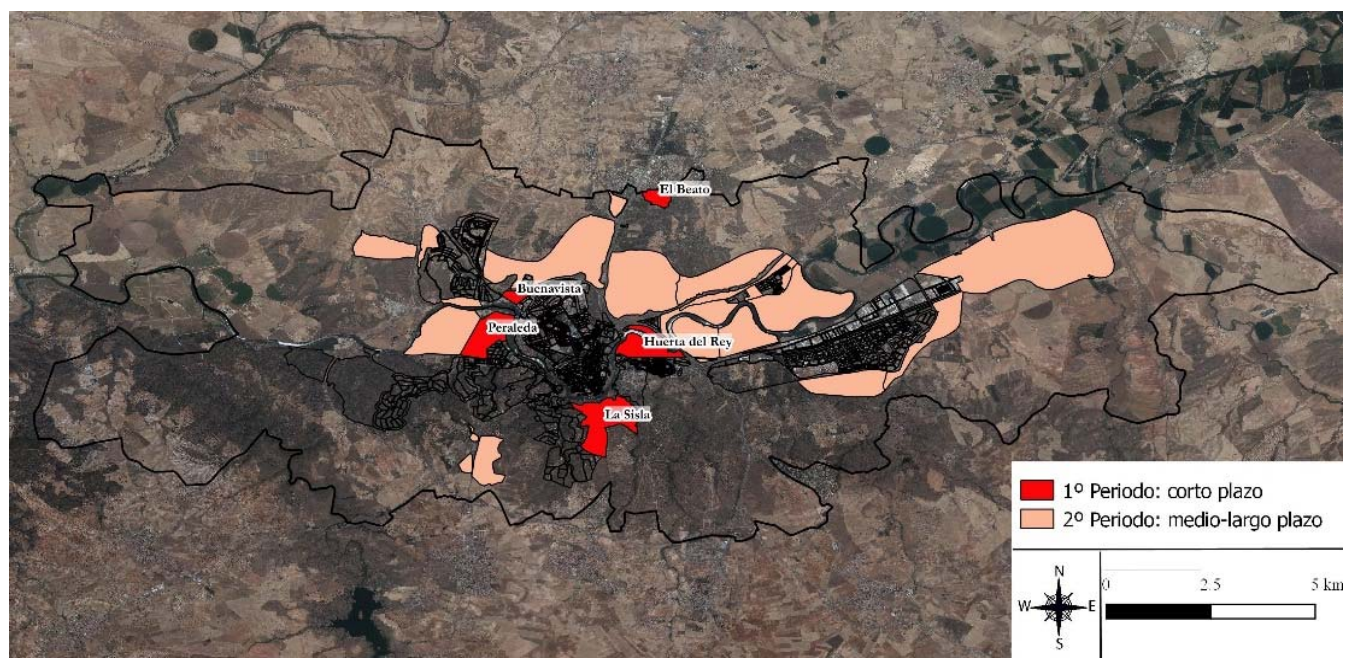

Fuente: Elaboración propia, a partir del POM (Ayuntamiento de Toledo, 2008), ortofoto del PNOA y Cartociudad (CNIG, 2017).

Igualmente, el devenir de la actual recesión paralizó la inmensa mayoría de las acciones que el POM preveía para articular su espectacular crecimiento urbanístico. Por otro lado, estas infraestructuras son la evidencia de que se crearía una enorme

${ }^{13}$ El volumen de ejecuciones hipotecarias se incrementó en un 621,3\% entre 2008-13 con respecto a 2002-08 en el municipio de Toledo (Méndez, Abad y Plaza, 2014, p. 31). 
extensión superficial de la ciudad y una clara dispersión. El POM contemplaba medidas como el soterramiento de las vías férreas, un túnel subterráneo por debajo del Tajo, nuevos puentes en el río, una plataforma de transporte colectivo metro ligero dirección este-oeste, un gran parque fluvial en el Tajo, etc. Una galería de nuevas infraestructuras previstas desde la óptica del boom inmobiliario. En los años de hiperdesarrollo urbanístico en España (y en especial, en Castilla-La Mancha) proliferó la abundancia de obras públicas, sobre todo en infraestructuras de comunicaciones y transporte, a la par de la explosión de construcción de nuevas viviendas. La crisis coincide con la aprobación del POM. El fomento de todo lo planificado en este sentido se ha limitado a la apertura de un segundo remonte mecánico de subida peatonal al centro histórico en el área de Safont, al este del casco. Se une al ya existente de Recaredo, al norte.

Figura 6. Construcción paralizada del Centro Regional de Expresión Artística Quixote (CREA).

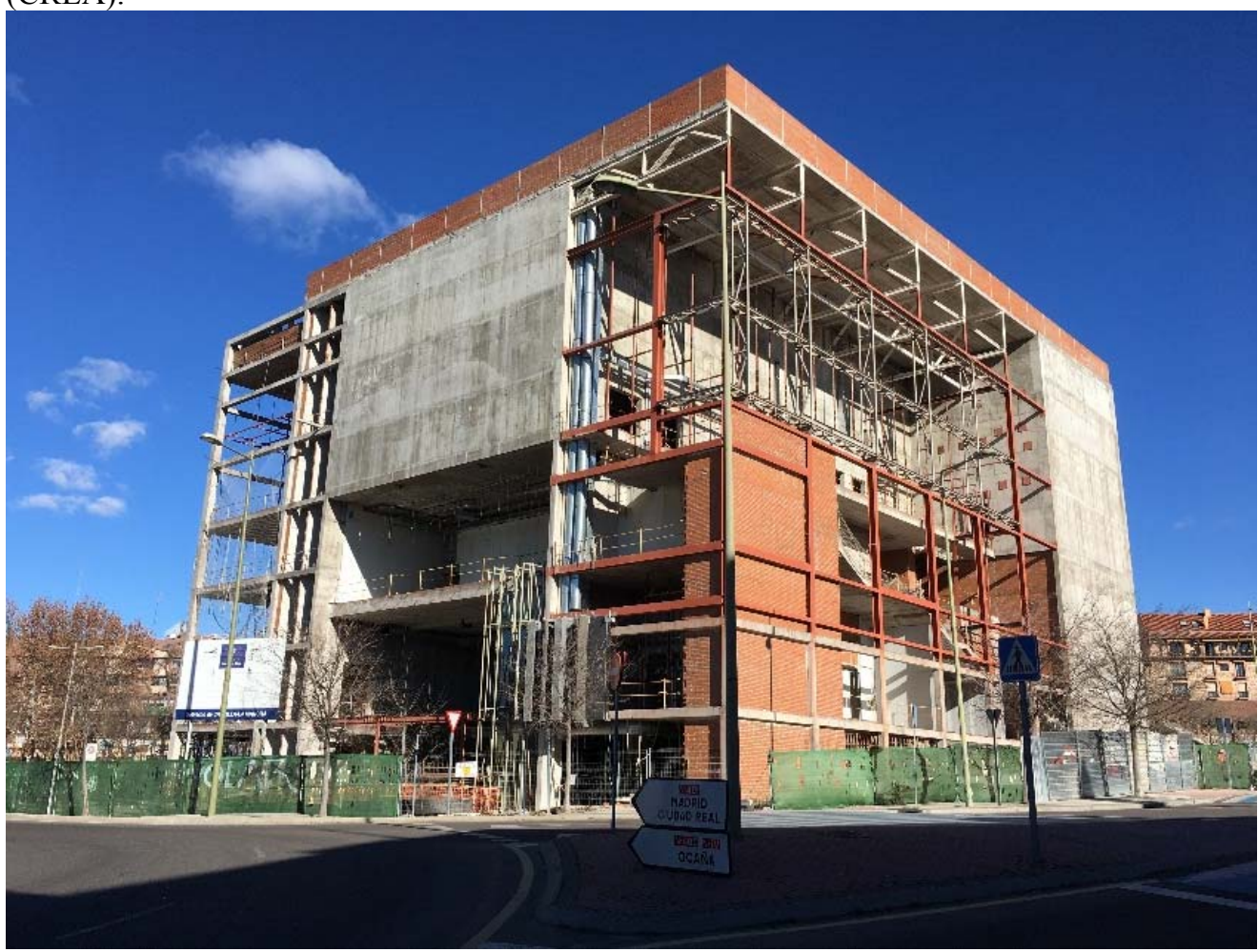

Fuente: Luis Alfonso Escudero Gómez (16/1/2017).

En relación a estas cuestiones, en la denominada «década prodigiosa» (Burriel, 2008) también hubo sitio para la proliferación de grandes equipamientos públicos, principalmente de carácter cultural y congresual. Toledo participó en esta «ola constructiva» a través de tres grandes edificios. El único que está abierto en la 
actualidad es el Palacio de Congresos de Toledo El Greco. Fue promovido por las tres administraciones de la ciudad, la autonómica, la provincial y la local en 2003 y se inauguró en 2012 con un coste final de 50 millones de euros, el doble del presupuesto inicial (Aparicio, 2013, p. 40). En segundo lugar, podemos señalar el Centro de Recepción de Visitantes Toletum. Fue iniciado en 2000 por la JCCM y el Ayuntamiento dentro del Plan de Excelencia Turística que entonces se ejecutaba. Se inauguró en 2007 en la zona del Salto del Caballo, en el acceso principal a Toledo desde Madrid. En 2011 cerró por falta de viabilidad económica (Pérez, 2014). Por último, debemos citar el Centro Regional de Expresión Artística Quixote (CREA). Se trata de una iniciativa de la JCCM presupuestada en 35 millones de euros (CONEXO, 2010). Se situaría cerca del Parque de las Tres Culturas, principal espacio verde de la ciudad, en la parte septentrional. Esta obra «faraónica», en palabras de los medios, se paralizó en 2014 y hoy el gobierno autonómico estudia qué hacer con el proyecto (Diario ABC, 2016). Mientras, su estructura de hormigón se alza en la ciudad toledana, como un paisaje devastado ${ }^{14}$ (Figura 6). Además, el Toletum y el Quixote han creado perturbaciones en el paisaje, cortando perspectivas de la ciudad histórica. Así lo denunciaba Zárate (2016), quien los calificaba como «artefactos» urbanos, al tiempo que reclamaba la necesidad de considerar el paisaje dentro de la ordenación del territorio y de la legislación del Patrimonio.

\subsection{Propuestas urbanísticas para el futuro de Toledo.}

El POM de 2007 se planteaba como la solución urbanística a corto y medio plazo para la ciudad de Toledo. Sin embargo, tanto los problemas judiciales surgidos tras su aprobación como, principalmente, la crisis económica han posibilitado que en la práctica todo lo planificado permanezca inédito. En este sentido, estamos ante un claro fracaso para el urbanismo de la ciudad. Este fiasco deberíamos verlo como un éxito dado que el POM ha suscitado las críticas de académicos, así como de la Real Sociedad Geográfica (Bosque y Zárate, 2006), de la Real Academia de Bellas Artes de San Fernando, de la Real Academia de la Historia, de la Real Academia de Bellas Artes y Ciencias Históricas de Toledo, de ICOMOS y de la Real Fundación de Toledo, entre otras instituciones y personas (Peris y Villa, 2009, p. 58). Además, la no ejecución hasta el momento del POM supone una nueva oportunidad para la ciudad de realizar un urbanismo menos desarrollista realmente sostenible, no basado en la calificación de suelo urbanizable y la construcción de miles de viviendas. El propio gobierno municipal lo reconoce cuando señala lo siguiente en la línea 2, acción 4 del Plan de Acción de la Estrategia de Toledo 2020 (Ayuntamiento de Toledo, 2015):

\footnotetext{
14 Término que cogemos prestado de la monografía del Observatorio Metropolitano de Madrid de 2013.
} 
Esta acción prevé la consolidación en Toledo de un modelo urbanístico sostenible, creando paisajes urbanos de calidad que fomenten la cohesión social y territorial. El modelo territorial de Toledo debe apostar por la configuración de una ciudad más habitable y atractiva, compacta y no dispersa, donde se dé la mixtura de usos, que introduzca un sistema de movilidad basado en el transporte público y en modos poco contaminantes, y que sea capaz de integrar y proteger su patrimonio natural y cultural para el disfrute de residentes y visitantes

Como afirma Burriel (2014), la reducida presión urbanística actual permitiría disponer del tiempo necesario para la reflexión. Consideramos que Toledo debe de aprovecharlo e intentar crear una ciudad más cohesionada. Su estructura urbana hace complejo alcanzar este fin. Para ello habría que avanzar en la conexión entre los distintos barrios entre sí. Es necesario que las áreas urbanas de la ciudad se encuentren. Al mismo tiempo, es fundamental evitar repetir los errores del pasado y acabar añadiendo a la ciudad nuevos y distantes sectores urbanos. Esto agravaría el problema estructural de Toledo.

Así, los intensos desarrollos previstos en la Vega Alta y el fuerte crecimiento planificado por el POM en la parte septentrional del municipio, en áreas aún vacías de urbanización, deberían evitarse. No hay una necesidad demográfica de urbanizar y edificar estos nuevos sectores urbanos. Toledo tiene su población estancada hoy y sus ritmos de crecimiento precedentes no demandan semejante expansión. Tampoco la hay económica. El sector inmobiliario permanece en crisis y así estará a medio plazo, más allá de la poca idoneidad de volver a modelos desarrollistas constructivos y especulativos. Por el contrario, es mucho más acertado y aconsejable compactar la ciudad, hacerla compleja y diversa. Se trata de crear infraestructuras sostenibles de accesibilidad y movilidad y espacios públicos y de uso ciudadano en las áreas intersticiales. No se trata de colmatarlas de miles de viviendas. Es decir, hacer verdadera ciudad.

Con este fin, resulta fundamental realizar un planeamiento urbanístico nuevo, distinto y alternativo para Toledo. En él, la sostenibilidad, la habitabilidad y la calidad de vida ciudadana deben mejorar verdaderamente. Un nuevo urbanismo que dé lugar a una urbanización que no sea puramente de tipo expansiva. Se trataría de renovar y aprovechar lo ya construido y solucionar los problemas estructurales actuales de la ciudad. Un planeamiento urbanístico que sea sostenible, y no solo en su memoria justificativa, y que renuncie definitivamente al modelo instaurado de calificación de suelo y construcción incesante. Al igual que Zárate (2007, p.17), se piensa para el futuro de Toledo un modelo de desarrollo urbanístico de calidad en sí mismo, que no sea el simple resultado de acumulación de áreas residenciales nuevas. Un urbanismo que apueste por un diseño atractivo, por unos entramados distintos de los actuales.

Para ello, la figura del plan general de ordenación urbana, o de ordenación municipal como se denomina en Castilla-La Mancha, no es la adecuada. Al menos, tal y como es entendida actualmente. Hoy se plantea la necesidad de emplear instrumentos de planificación de carácter integrado que hagan frente a los retos territoriales y a los nuevos problemas con un enfoque se encamine más hacia 
funciones de desarrollo territorial y de coordinación (gobernanza) que a la simple ordenación de los usos del suelo (González, 2012, p. 285). Sin embargo, la delimitación del nuevo suelo a urbanizar sigue siendo el eje fundamental de la idea de futuro de la ciudad en el planeamiento municipal toledano.

El nuevo urbanismo de la ciudad debe ser claramente participativo. Esta es una cuestión esencial. Efectivamente, la propuesta del POM de 2005 (que no el documento modificado y aprobado en 2007) tuvo un largo proceso de elaboración con información pública por diferentes medios y a lo largo de todas sus etapas, no solo en el momento de exposición al ciudadano. No obstante, como sucede habitualmente en el planeamiento urbanístico español, se trató de una participación regulada e institucionalizada que tiende a legitimar lo que ya está decidido previamente (Benach, 2016, p. 70). La sociedad toledana ha demostrado su deseo, capacidad y disposición para contribuir activamente y de un modo claramente racional en el diseño del Toledo del mañana. Así lo ha hecho cuando su demanda fue tenida en cuenta por el TSJCLM y por el Tribunal Supremo y logró anular el POM, aunque el proceso judicial aún no haya culminado. Precisamente, esto se consiguió porque no se había tenido en cuenta la participación pública.

Cualquier planeamiento urbanístico en los próximos años debe contar específicamente con una implicación abierta de la ciudadanía. No solo a nivel consultivo como se ha realizado hasta ahora. Sin embargo, se está comenzando a redactar un nuevo plan de ordenación municipal en Toledo sin que haya ninguna información pública de cómo se está haciendo ni tampoco ninguna participación o consulta posible sobre este futuro plan por el momento. Solo aparecen noticias aisladas en los medios de que el gobierno local está haciendo un nuevo POM. El municipio de Toledo ha abierto una $\mathrm{web}^{15}$ que denomina portal de transparencia $y$ buen gobierno. Una útil herramienta que podía utilizar para hacer esta nueva ordenación urbana de la ciudad de una forma mucho más pública y colaborativa. Esto es, de una manera mucho más abierta y transparente, utilizando los propios adjetivos de la indicada web municipal.

La idea de reparar el territorio debe predominar en ese planeamiento futuro. No la de expandirlo. Es necesario hacer un inventario objetivo del Toledo actual y un balance de su proceso urbanizador. Al mismo tiempo, hay que realizar un análisis riguroso de la dinámica demográfica y territorial. Como indicamos, también ha de haber una implicación de la administración pública para un modelo territorial diferente y se ha de contar con la contribución activa de la ciudadanía. Se tiene que aplicar un urbanismo donde no se fomente más vivienda ni haya más promociones inmobiliarias que las estrictamente justificadas, con una aceptación social previa y con un proyecto realmente sostenible. Asimismo, las nuevas infraestructuras han de ser verdaderamente estratégicas y los nuevos equipamientos, sociales, no solamente de imagen. Finalmente, es obligatorio salvaguardar aquellos terrenos cuya

\footnotetext{
${ }^{15} \mathrm{https}: / /$ www.toledo.es/toledo-abierto/
} 
urbanización provocaría daños irreversibles en la calidad del entorno y del paisaje. Se aboga por dejar fuera del proceso urbanizador la Vega Alta de Toledo y no intensificar más el crecimiento en las colinas del norte del municipio. Si realmente se quiere cambiar el modelo territorial de ciudad en los próximos años, el camino no es la calificación de una cantidad de suelo urbanizable superior al suelo urbano consolidado. Es el momento de descalificar estas superficies, revocar el POM e incluso plantearse la posibilidad de desurbanizar suelo.

Unas políticas activas de rehabilitación de viviendas y de regeneración urbana son necesarias en los actuales barrios residenciales. Se han de incluir medidas incentivadoras para la ocupación de las viviendas vacantes, cuestión que ya demandaba López de Lucio para las ciudades españolas en 1993. Toledo necesita aplicar realmente otra de las acciones que recoge el Plan de Acción de la Estrategia 2020 (línea 6, acción 3, Ayuntamiento de Toledo, 2015): estrategias innovadoras para la recuperación económica, urbanística y social de los diferentes barrios de la ciudad. En este sentido, no se trata tanto de rellenar los espacios intersticiales con más viviendas. Evidentemente hay que utilizarlos para articular la estructura urbana fragmentada toledana. Hay que dinamizar su comunicación y convertirlos en piezas armónicas, no colmatarlos.

El escenario que sigue planteando el POM de 2007 se vislumbra como una repetición del modelo constructivo e inmobiliario especulativo de las pasadas décadas como López y Rodríguez (2010, p. 480) explican para el caso de toda España. Es la opción que siguen defendiendo fuerzas políticas locales como el modelo que crea riqueza y empleo para nuestra gente y para nuestra ciudad con el crecimiento de Toledo (Europa Press, 2015a).

En este trabajo, como Nel.Lo (2012, p. 29), se opta por otro deseable escenario. Hay que evitar que se continúe degradando el territorio. Se ha de promover su ordenación a partir de principios de protección de los valores del paisaje, de la sostenibilidad ambiental y de la equidad social. Se trataría de transitar desde una topografía del lucro (Schulz-Dornburg, 2012) hacia un nuevo urbanismo que beneficie al conjunto de la sociedad.

\section{Discusión}

El artículo no cierra el análisis científico sobre el proceso urbanizador de Toledo. No lo puede hacer por ser algo en evolución continua y porque en este momento la ordenación urbana de la ciudad está entre la disyuntiva de mantener el POM, redactar uno nuevo o, incluso, recuperar el PGOU de 1986 con modificaciones (Álvarez, 2017 y Bachiller, 2017). En este sentido, el campo de estudio sigue claramente abierto.

El urbanismo en sí es una cuestión de eterno debate. Por esta razón, el presente análisis y las propuestas presentadas son claramente discutibles. Se asume este hecho. En el texto se ha pretendido mostrar claramente un posicionamiento y razonarlo académicamente. Aun así, se ha de tener en cuenta que, por ejemplo, políticos locales 
siguen respaldando el modelo de continuo crecimiento y de la promoción de vivienda sin fin para el desarrollo económico de la ciudad.

Finalmente, los límites de la estructura del trabajo obligan a hacer una investigación parcial. No se ha podido profundizar en todas las dimensiones posibles. En este sentido, se considera que el principal déficit ha sido ignorar la planificación relacionada con el centro histórico. No obstante, Zárate (2007) ya abordó suficientemente las implicaciones del POM en el casco antiguo y los paisajes culturales toledanos. Solo sería necesario un estudio más pormenorizado sobre el Plan Especial de Los Cigarrales de Toledo aprobado en 2007 así como del catálogo de nuevos espacios protegidos fuera del casco que el POM ha realizado. De forma general, si se valora la relación del POM con la trama urbana y el paisaje cultural heredado por Toledo se puede tener en cuenta el informe realizado por el Consejo Internacional de Monumentos y Sitios (ICOMOS) en 2006 donde se señala que:

El POM no tiene en cuenta la totalidad de la protección de los espacios y valores protegidos señalados en el expediente de declaración de Toledo como Patrimonio Mundial. La protección propuesta se limita al Casco Histórico, Circo Romano, Cigarrales y accesos desde la carretera de Madrid, obviando una gran parte del perímetro de protección (Zona Tampón), principalmente amplios espacios de la zona de la Vega del Tajo (Alta y Baja) en los que altera su clasificación urbanistica de suelo rustico "no urbanizable de especial protección" para convertirlo en "suelo urbanizable". Este hecho significa la pérdida irreparable de la autenticidad e integridad de una parte muy significativa de los valores culturales y paisajísticos por los que fue declarada Toledo ciudad Patrimonio Mundial. (ICOMOS, 2006, p. 11)

\section{Conclusión}

La ciudad de Toledo tiene un plan de ordenación urbana, el POM de 2007, que califica más suelo urbanizable que suelo urbano consolidado tiene la ciudad. Un plan que contempla la promoción de una cantidad de viviendas superior al total de las censadas en el presente. El POM se presenta a sí mismo como un modelo territorial sostenible cuyo fin es articular una urbe hoy desestructurada. En realidad, acaba aplicando la errónea idea de que calificando una cantidad enorme de suelo urbanizable se abaratará el mercado del suelo y serán más accesibles las viviendas. Una forma de ordenar ciudad que ha originado en Toledo, y en la mayoría de las ciudades españolas donde se ha aplicado, un crecimiento urbanístico especulativo. Uno de los pilares de la «década prodigiosa» del sector inmobiliario en el Estado, donde suelo y vivienda en vez de abaratarse fueron incrementando progresivamente su valor.

El denominado boom inmobiliario estalló con la crisis de 2008. Desde entonces, esta actividad económica está paralizada en España. Son tiempos para pensar un modelo urbanístico totalmente distinto, pero Toledo justó aprobó el señalado POM un 
año antes de la crisis. El plan ha experimentado una larga travesía judicial, de la cual aún sobrevive, pero que probablemente terminé por anularlo de manera definitiva en corto plazo. La crisis ha imposibilitado que se ejecutase prácticamente nada de lo planificado: ni las nuevas áreas urbanizadas y sus miles de viviendas ni las nuevas infraestructuras. No obstante, el suelo calificado sigue siendo urbanizable y Toledo es una de las ciudades de España con un mayor potencial residencial.

Llegados a este punto, se concluye que el POM de 2007 debe ser abandonado. Se debe aplicar un nuevo urbanismo realmente sostenible, con la participación ciudadana, con racionalidad y con fines sociales, no lucrativos. Se ha de abandonar la urbanización de la Vega Alta y se ha de descalificar suelo. Asimismo, se ha de trabajar en una verdadera articulación del espacio urbano consolidado, reorganizando los barrios y comunicándolos entre sí aprovechando los numerosos espacios intersticiales existentes mediante ideas urbanísticas que den lugar a un uso social adecuado de estas áreas, no a través de su compactación y colmatación con miles de viviendas sino con espacios públicos y de mejora de la calidad de vida de los ciudadanos.

El gobierno municipal también reconoce la necesidad de un nuevo urbanismo en Toledo en su documento sobre las estrategias a desarrollar en la ciudad para el 2020 y en los medios cuando proclama que está redactando un nuevo POM (al tiempo que defiende enconadamente la legalidad del actual). La contribución activa de la sociedad debería ser considerada, ya mismo, en ese planeamiento futuro de la ciudad. La expansiva calificación de suelo urbanizable y la promoción de miles viviendas deberían ser un recuerdo del pasado.

\section{Referencias bibliográficas}

Asociación Española de Técnicos Urbanistas (2017): Disponible en

Álvarez Ahedo, I. (2004): El urbanismo del término municipal de Toledo en el siglo XX. Toledo, Colegio de Arquitectos de Castilla-La Mancha.

Álvarez Ahedo, I. (2017): El plan general de Toledo: antecedentes, estructura y perspectivas. Consultado el 21/12/2017.

Disponible en http://aetu.es/app/download/5809674318/POM+Toledo.compressed.pdf.

Aparicio Guerrero, A. E. (2013): Los centros históricos de Toledo y Cuenca. Nuevos equipamientos socioculturales para la recuperación funcional. Polígonos. Revista de Geografía, 24, 19-56.

Ayuntamiento de Toledo (2008): Plan de Ordenación Municipal de Toledo de 2007. Documento 2008. Consultado en múltiples ocasiones en 2016 y 2017.

Disponible en https:/www.toledo.es/servicios-municipales/urbanismo/plan-de-ordenacionmunicipal-pom/.

Ayuntamiento de Toledo (2015): Toledo Estrategia 2020. Consultado el 15/12/2016. Disponible en http://www.ayto-toledo.org/toledo2020/toledo2020.asp.

Ayuntamiento de Toledo (2016): Evolución de la población por barrios y distritos 2016. Consultado el 24/12/2016. Disponible en 
http://www.ayto-toledo.org/padron/EvolucionPoblacionBarriosDistritos2016.pdf.

Benach Rovira, Núria (2016): ¿Sociedades rotas? Cuestiones de vivienda, políticas urbanas y barrios en conflicto. En Brandis, D.; Del Río, I. y Morales, G. (Coords.): Estudios de Geografía Urbana en tiempos de crisis. Madrid, Biblioteca Nueva, 65-80.

Burriel de Orueta, E. L. (2008): La «década prodigiosa» del urbanismo español (1997-2006). Scripta Nova. Revista Electrónica de Geografía y Ciencias Sociales, XII, 270. Consultado el 4/1/2017. Disponible en http://www.ub.edu/geocrit/-xcol/383.htm.

Bachiller, Carmen (2017): El ayuntamiento de Toledo duda entre quedarse con el POM de 2007 o volver a 1986. Eldiario.es, 7/4/2017. Consultado el 19/4/2017.

Disponible en http://www.eldiario.es/clm/Ayuntamiento-Toledo-debera-quedarsePOM_0_630637398.html.

Bachiller, Carmen (2017b): El desafío de Toledo: cómo evitar entorpecer el desarrollo volviendo al plan urbanístico de 1986. Eldiario.es, 6/11. Consultado el 7/11/2017. Disponible en http://www.eldiario.es/clm/Toledo-entorpecer-desarrollo-volviendourbanistico 0 705179834.html.

Bosque Maurel, J. y Zárate Martín, M. A. (2006): Informe de la Real Sociedad Geográfica sobre el proyecto de Plan de Ordenación Municipal de la ciudad de Toledo 2006. Boletín de la Real Sociedad Geográfica, CXLII, 375-453.

Burriel de Orueta, E. L. (2014): El estallido de la burbuja inmobiliaria y sus efectos en el territorio. En Albertos, J.M. y Sánchez, J.L. (Eds.): Geografía de la crisis económica en España. Valencia, Universidad de Valencia, 101-140.

Campos Romero, Ma L.; Díaz Moreno, J. L.; García Fraile, D.; Martín Martín, J. y SánchezHorneros Gómez, A. (1988): Toledo: estudio geográfico-urbanístico del casco histórico. En AA. VV.: Toledo ¿Ciudad viva? ¿Ciudad muerta? Toledo, Colegio Universitario de Toledo, 3-74.

Campos Romero, Ma L. y Escudero Gómez, L. A. (2007): Planificación urbana de Toledo y el crecimiento en áreas de protección. Las Vegas del Tajo. En Gutiérrez Ronco, S. y Sanz Donaire, J. J. (Eds.): Homenaje al Profesor José Manuel Casas Torres. Madrid, Universidad Complutense, 397-414.

Castro, E. (1986): El plan de urbanismo de Toledo, aprobado tras 10 años de trámites. Diario El País, 21/11/1986. Consultado el 31/12/2016. Disponible en http://elpais.com/diario/1986/11/21/espana/532911633_850215.html

CONEXO Diario Online de Congresos, Reuniones e Incentivos (2010): El Ayuntamiento de Toledo concede la licencia de obras para el 'Quixote CREA', 16/4/2010. Consultado el 4/1/2017. Disponible en http://www.nexotur.com/noticia/29300/CONEXO/ElAyuntamiento-de-Toledo-concede-la-licencia-de-obras-para-el-Quixote-CREA-quecontara-con-un-auditorio-con-700-plazas.html.

Centro Nacional de Información Geográfica (CNIG) (2017): Centro de descargas: ortofotos del Plan Nacional de Ortografía Aérea (PNOA) y Cartociudad. Consultado el 9/1/2017. Disponible en http://centrodedescargas.cnig.es/CentroDescargas/catalogo.do

Consejo General del Poder Judicial (CENDOJ) (2016): Buscador jurisprudencia. Consultado en múltiples ocasiones en 2016. 
Disponible en http://www.poderjudicial.es/search/indexAN.jsp?org=ap-tsj\&comunidad=07 (para el Tribunal Superior de Justicia de Castilla-La Mancha) y http://www.poderjudicial.es/search/ (para el Tribunal Supremo).

Consejo Internacional de Monumentos y Sitios (ICOMOS) (2006): Informe del Comité Español del Consejo Internacional de Monumentos y Sitios (ICOMOS) sobre el proyectado plan de ordenación de la ciudad de Toledo (POM, 2005). Consultado el 18/1/2017. Disponible en http://www.ugr.es/ ophe/020DOCUMENTACION/004003c.pdf

Diario ABC (2016): Page visita el edificio a medio construir del «Quixote Crea», 6/12/2016. Consultado el 4/1/2017. Disponible en http://www.abc.es/espana/castilla-lamancha/toledo/ciudad/abci-page-visita-edificio-medio-construir-quixote-crea201612061328 noticia.html

El Digital Castilla-La Mancha (2017): Milagros Tolón anuncia recurso de casación en Toledo contra la nulidad del POM de 2007, 24/5/2017. Consultado el 24/5/2107. Disponible en http:/www.eldigitalcastillalamancha.es/actualidad/478902455/Milagros-Tolon-anunciarecurso-de-casacion-en-Toledo-contra-la-nulidad-del-POM-de-2007.html.

Escudero Gómez, L.A. y Gómez Gutiérrez, E. J. (2007): El Plan de Descongestión Industrial de Madrid en Castilla-La Mancha: una reflexión geográfica. Estudios Geográficos, vol. LXVIII, 263, 497-526. DOI: http://dx.doi.org/10.3989/egeogr.2007.i263.66.

Europa Press (2015a): Labrador pide soluciones a los problemas urbanísticos de Toledo, 12/7/2015. Consultado el 3/1/2016. Disponible en http://www.europapress.es/castillalamancha/noticia-labrador-pp-pide-tolon-tome-soluciones-problemas-urbanisticos-auto-tcpom-20150712111544.html.

Europa Press (2015b): Tolón afirma que el POM de 2007 “está totalmente vigente”, 2/10/2015. Consultado el 3/1/2017.

Disponible en http:/www.europapress.es/castilla-lamancha/noticia-tolon-afirma-pom-2007totalmente-vigente-sentencia-tc-20151002181811.html.

Europa Press (2015b): Tolón afirma que el POM de 2007 “está totalmente vigente”, 2/10/2015. Consultado el 3/1/2017.

Disponible en http:/www.europapress.es/castilla-lamancha/noticia-tolon-afirma-pom-2007totalmente-vigente-sentencia-tc-20151002181811.html. Europa Press (2017): Fomento pedirá al TC que aclare la sentencia que anula un artículo de la LOTAU, 22/2/2017. Consultado el 11/4/2017. Disponible en http://www.europapress.es/castillalamancha/noticia-fomento-pedira-tc-aclare-sentencia-anula-articulo-lotau20170222102917.html.

Fariña Tojo, J. (1993): Influencia del medio físico en el origen y evolución de la trama urbana de la ciudad de Toledo. Madrid, Dpto. de Publicaciones E.T.S. de Arquitectura.

Foro GTT y Orbe Cano, A. (1986): Plan General de Ordenación Urbana de Toledo, 1986, inédito. Consultado en la Concejalía de Urbanismo del Ayuntamiento de Toledo en 2007.

Franzen, J. (2011): Libertad. Barcelona, Ediciones Salamandra.

García Cuesta, J. L. (2000): De la urgencia social al negocio inmobiliario. Promoción de viviendas y desarrollo urbano en Valladolid (1960-1992). Valladolid, Ayuntamiento y Universidad de Valladolid. 
García Vázquez, C. (2004): Ciudad hojaldre. Visiones urbanas del siglo XXI. Barcelona, Gustavo Gili.

González Medina, M. (2012): La planificación estratégica de "nueva generación”: ¿Cómo evaluar su impacto como instrumento de gobernanza territorial?. Revista Geopolítica(s), vol. 3, 2, 271-291. DOI: 10.5209/rev_GEOP.2012.v3.n2.40400.

Instituto Nacional de Estadística (1991): Censo de Población y Viviendas 1991. Consultado el 14/12/2016. Disponible en

$\mathrm{http} / /$ www.ine.es/jaxi/menu.do?type $=$ pcaxis $\&$ path $=\% 2 \mathrm{Ft} 20 \% 2 \mathrm{Fe} 243 \&$ file $=$ inebase $\& \mathrm{~L}=0$

Instituto Nacional de Estadística (2001): Censo de Población y Viviendas 2001. Consultado el 14/12/2016. Disponible en http://www.ine.es/censo2001/

Instituto Nacional de Estadística (2011): Censo de Población y Viviendas 2011. Consultado el 14/12/2016. Disponible en

http://www.ine.es/censos2011_datos/cen11_datos_resultados.htm.

Instituto Nacional de Estadística (INE) (2015): Padrón Municipal 2015, consultado el 29/12/2016. Disponible en

http://www.ine.es/jaxi/menu.do?type=pcaxis\&path=/t20/e245/\&file=inebase.

Lois González, R. C.; González Pérez, J. M. y Escudero Gómez, L. A. (2012): Los espacios urbanos. El estudio geográfico de la ciudad y la urbanización. Madrid, Biblioteca Nueva.

López de Lucio, R. (1993): Ciudad y urbanismo a finales del siglo XX. Valencia, Universitat de València.

López López, A. (2005): Desarrollo sostenible: medio ambiente y turismo en las ciudades históricas: el caso de Toledo. Observatorio Ambiental, 8, 331-344.

López, I. y Rodríguez, E. (2010): Fin de ciclo. Financiarización, territorio y sociedad de propietarios en la onda larga del capitalismo hispano (1959-2010). Madrid, Traficantes de Sueños.

Lorente Toledo, E. y Vázquez González, A. (2006): La ciudad de Toledo en la época del Quijote. En Pillet, F. y Plaza, J. (Coords.): El espacio geográfico del Quijote en Castilla-La Mancha. Cuenca, Universidad de Castilla-La Mancha, 107-139.

Lynch, K. (1985): La buena forma de la ciudad. Barcelona, Gustavo Gili.

Méndez Gutiérrez del Valle, R.; Abad Aragón, L. y Plaza Tabasco, J. (2014): Geografía de las ejecuciones hipotecarias en España. Madrid, Fundación $1^{\circ}$ de Mayo, consultado el 21/12/2016. Disponible en http://www.1mayo.ccoo.es/nova/files/1018/Estudio84.pdf.

Ministerio de Fomento (2014): Sectores residenciales en España 2014. Consultado el $17 / 12 / 2016$.

Disponible

en

http://www.fomento.gob.es/MFOM.CP.Web/handlers/pdfhandler.ashx?idpub=BAW03.

Ministerio de Fomento (2017): Sistema de información urbana (SIU). Consultado el 9/1/2017. Disponible en http://visorsiu.fomento.es/siu/PortalSiu.html.

Mitscherlich, A. (1977): Tesis sobre la ciudad del futuro. Madrid, Alianza Editorial.

Muelas Jiménez, M. y Parrilla Gorbea, E. (2008): Plan de Ordenación Municipal de Toledo, 2007. Urban, 13, 34-67. Consultado el 21/12/2016. Disponible en http://oa.upm.es/21334/1/INVE_MEM_2008_144310.pdf.

Nel.Lo, O. (2012): Herencias territoriales, exploraciones geográficas y designios políticos. En Schulz-Dornburg, J.: Ruinas modernas. Una topografía del lucro. Barcelona, Ámbit, 23-29. 
Objetivo Castilla-La Mancha (2016): Tres nuevas resoluciones del Tribunal Constitucional "cierran el círculo" y confirman que el POM de Toledo "es eficaz y está vigente", 29/6/2016. Consultado el 3/1/2017.

Disponible en http://www.objetivocastillalamancha.es/contenidos/toledo/tres-nuevasresoluciones-del-tribunal-constitucional-cierran-el-circulo-y-confirman-que-el-pom-detoledo-es

Observatorio Metropolitano de Madrid (Eds.) (2013): Paisajes devastados después del ciclo inmobiliario: impactos regionales y urbanos de la crisis. Madrid, Traficantes de Sueños.

Pais Rodríguez, R. (2004): El agente urbanizador o la conversión de una función pública en la actividad empresarial privada sin riesgo. Revista de Derecho de la Unión Europea, 7, 313343.

Parada Vázquez, J. R. (1999): La degeneración del Derecho urbanístico español: del urbanismo de obra pública de Cerdá al urbanismo de obra privada. En García-Bellido García de Diego, J. (Coord.): Cerdá y su influjo en los ensanches de población. Madrid, Ministerio de Fomento, 75-90.

Pérez, J. A. (2014): El Toletum no tiene quien le quiera. Diario ABC, 7/6/2014. Consultado el 4/1/2017. Disponible en http://www.abc.es/toledo/ciudad/20140607/abci-toletum-nadiequiere-201406071949.html.

Peris Sánchez, A. y Villa, Ramón (2009: Territorio: historia, cartografía e imagen”. En Gallego García, M M. (Coord.): La Vega Baja de Toledo. Toledo,Toletum Visigodo,21-68.

Ponce Herrero, G. (2006): La fragmentación de la forma urbana en la Comunidad Valenciana. En Ponce Herrero, G. (Ed.): La ciudad fragmentada. Nuevas formas de hábitat. Alicante, Universidad de Alicante, 89-130.

Rullán Salamanca, O. (2003): Economía y sostenibilidad de las ciudades: entre la desregulación y la planificación. En López Trigal, L.; Relea Fernández, C. E. y Somoza Medina, J. (Eds.): La ciudad. Nuevos procesos, nuevas respuestas. León, Universidad de León, 151-168.

Sainz Gutiérrez, V. (1999): La cultura urbana de la posmodernidad. Aldo Rossi y su contexto. Sevilla, Alfar.

Sánchez Lubián, E. (2015): Mario Muelas (1943-2015): referente de la rehabilitación patrimonial. Diario ABC, 3/2/2015. Consultado el 31/12/2016. Disponible en http://www.abc.es/toledo/ciudad/20150203/abci-mario-muelas-1943-2015201502032156.html.

Sassen, S. (2014): La ciudad según... En Denis, J.P. y Pourquery, D. (Eds.): El atlas de las metrópolis. Valencia, Fundación Mondiplo, 15.

Schulz-Dornburg, J. (2012): Ruinas modernas. Una topografía del lucro. Barcelona, Ámbit.

Tomé Fernández, S. (2007): Los centros históricos de las ciudades españolas. Revista Ería, 72, $75-78$.

La Tribuna de Toledo (2017): El POM de nunca acabar, 9/11/2017. Consultado el 10/11/2017. Disponible en http:/www.latribunadetoledo.es/Noticia/Z535A01EF-E9B8-DA910C8D35C764C16509/El-POM-de-nunca-acabar.

Troitiño Torralba, L. (2005): La oferta patrimonial y cultural de la ciudad de Toledo y su funcionalidad turística". En Ortega, E., González, L. y Pérez, E. (Eds.): VII Fórum 
Internacional sobre las Ciencias y las Técnicas y el Arte Aplicadas al Marketing. Academia y Profesión. Madrid, Universidad Complutense de Madrid, 415-434.

Zárate Martín, M. A. (2007): Toledo. Planeamiento y especulación en ciudades históricas. Anales de Geografía, vol. 27, 1, 151-175.

Zárate Martín, M. A. (2016): "Paisajes culturales urbanos, oportunidad para la conservación del patrimonio y el turismo sostenible”. Estudios Geográficos, vol. LXXVII, 281, pp. 693728. DOI: 10.3989/estgeogr.201624.

Zárate Martín, M.A. y Vázquez González, A. (1982): El casco histórico de Toledo. ¿Un espacio urbano vivo?. Toledo, Zocodover.

\section{Agradecimientos:}

Este articulo forma parte del proyecto de investigación Dinámicas de urbanización y políticas urbanísticas en ciudades medias interiores. De expansión y dispersión a reformulación: ¿Hacia un urbanismo más ¿urbano??, subvencionado por el Programa Estatal de Investigación, Desarrollo e Innovación Orientada a los Retos de la Sociedad, Convocatoria 2015, Modalidad 1: «Proyectos de I+D+I» del Ministerio de Economía y Competitividad con referencia CSO2015-63970-R (MINECO/FEDER).

Un agradecimiento especial a la profesora María Lourdes Campos a la que debo mi interés por la ciudad de Toledo.

Agradecer al catedrático Rubén Lois González su lectura previa y sugerencias al artículo.

Finalmente, agradecer a los dos evaluadores externos sus observaciones y comentarios. Sin duda, sus propuestas han servido para una gran mejora del artículo, quedando los posibles errores finales a cargo exclusivamente del investigador. 